Vol: 03,Pg: 01-12, Yr:2022

\title{
Antimicrobial Properties of Different Kinds of Honey and its Benefits
}

\author{
Debasmita Chakraborty \\ Maulana Abul Kalam Azad University of Technology, West Bengal. BF Block, Sector 1, \\ Bidhannagar, Kolkata, West Bengal 700064 \\ Corresponding: debasmitac9@gmail.com
}

\begin{abstract}
:
Honey is a well-known ancient remedy for the treatment of infected wounds, surgical wounds, burns, skin/peptic ulcers, inflammations etc. It is highly popular for its antimicrobial, antiseptic, antioxidants and immunomodulatory roles. The healing property of honey provides antibacterial activity and wound repair as well. Honey is extremely viscous in nature to prevent further infection. The antimicrobial property is coming due to the enzymatic production of hydrogen peroxide. The hygroscopic nature of honey plays an antibacterial role. It also has been reported in many journals that honey is described as reservoir of microorganism as it contains bacteria, fungi, yeast, moulds etc. The main aim of this research work is to study antimicrobial properties of different kinds of honey by preparing LB plates with different honey samples to check the microbial growth and then the characterization of the different
\end{abstract}

microorganisms by the following methods of gram staining, disk diffusion methods, SEM analysis, graphical analysis etc. An ample of literature search was done on the very interesting topic of honey using Books, Scientific Journals, Google Search. Relevant Scientific Journals were collected to gather the concepts on the antimicrobial properties as well as the microbial contents of honey and the inferences of these. The development process of honey, preservation of honey maintain the presence of microorganisms. Most of them are in inactive forms and hardly surviving within the honey as it has some properties like hygroscopicity, hyperosmolarity, acidity, hydrogen peroxide contents, antibiotics properties, wound-healing properties etc. Finally this work will conclude with the study of microorganisms present within the honey, how this honey becomes beneficial to treat selective wounds and its antimicrobial roles as well. 
Keywords: Honey, Glucose Oxidase, Gluconic Acid, Non-peroxide Honey, Medihoney, Manuka Honey, Immunomodulatory Property, Wound Repair, Wound Healing, Antibacterial Activity, Antiseptic Property, Antimicrobial Property, Antioxidant, Hygroscopicity, Nectar, Pathogens, MRSA, VRE.

\section{Introduction:}

In various research journals, honey was described as one of the world's oldest natural medicinal substance. From long time back or since the origin of mankind, honey is used as traditional medicine and it is produced by Apismelifera [1, 2]. It is purely natural sweetener, produced by honey bees from nectar, blossoms, or from the secretion of the living parts of plants or excretions of plants, which are collected and stored by honey bees in the honeycomb [1]. Honey production starts with collected nectar, pollen from flowers but nectar is only used to prepare honey and it is a sugar rich liquid component produced by plants in glands called nectarins or nectaries, either within flower to attract pollinating animals by which extrafloralnectaries which provide nutrient source to animal mutualists for herbivore protection. Nectar contains water with sugar $(25-70 \%)$. It is sucked by the inserted proboscis of honey bees inside the flowers nectary and it goes through the oesophagus to the thorax and finally to the abdomen. Pollen is transported to pollen busket of hive whereas nectar reaches stomach. Nectar is placed into the different wax cells of honeycomb. Within few days, these cells get covered with a layer of wax which is removed later when bees want to eat honey and the bees produce Invertase enzyme to break sucrose molecule into glucose $(31.3 \%)$ and fructose $(38.2 \%)$ by evaporating excess water to make the honey more concentrated with approximately $83 \%$ sugar and $17 \%$ water and this concentrated honey is suitable for yeast or other microbial growth [3]. The other sugars within the honey include disaccharides such as maltose, isomaltose, sucrose or few oligosaccharides. The organic acid, Gluconic acid constitutes $0.57 \%$ of honey, which is a byproduct of enzymatic digestion of glucose and it is important to maintain acidity $(\mathrm{pH} 3.2-4.5)$ and taste [4]. Some minerals $(0.17 \%)$ are also present such as potassium, calcium, copper, iron, phosphorus, manganese, nitrogenous compounds, and vitamin $\mathrm{C}, \mathrm{B}$ (thiamine), B2 complex like riboflavin, nicotinic acid, B6 pantothenic acid along with some enzymes like invertase (saccharase), diastase (amylase), glucose oxidase and these play an important role in 
the formation of honey.Honey is extremely viscous in nature to prevent further infection [5].For hygroscopic nature of honey, it can draw moisture out of the environment and it dehydrates bacteria ultimately and honey has also high sugar content and low pHlevel to prevent microbial growth. The surface tension of honey with high viscosity is responsible for the foaming characteristics of honey. The liquid honey colour varies from watery clear and colourless to dark amber to black due to different dilutions or concentrations of caramelized sugar, different botanical origin, age, storage conditions. Its transparency depends upon the quantity of suspended particles like pollen $[6,7]$.

\section{Microbes in Honey:}

Which microorganism can tolerate concentrated sugar, low $\mathrm{pH}$ or acidic environment, hygroscopicity, and other antimicrobial characters, only those microorganisms can survive within honey. The key sources of microbial contamination in honey including pollen, digestive tracts of honeybees, dust, air particles, dirt and flowers. Microbes found in honeycomb are bacteria, fungi, yeast, moulds etc. coming from bees, raw materials (nectar), or other external sources. Larvae are inoculated by feeding of nectar and pollen by worker honeybees though it was initially sterile [8]. Sackelt reported Bacillus, Micrococcus, Saccharomyces species were isolated from honeycomb, adult honeybees and faeces of larvae [9]. The intestinal microbial loads of bees contain $1 \%$ yeast, $27 \%$ Grampositive bacteria including Bacillus, Bacteridium, Streptococcus, Clostridium spp., $\quad 70 \%$ Gram-negative bacteria including Achromobacter, Citrobacter, Enterobacter, Erwinia, Escherichia coli, Flavobacterium, Proteus, Klebsiella, Pseudomonas [10].Bacillus sp. are the most prevalent followed by Gram-variable pleomorphic bacteria. Mould, Actinomycetes, Gram-negative rods (i.e. Enterobacteriaceae) and yeast are isolated whereas Streptomyces spp. are recovered from larvae. Bacillus, Enterobacteriaceae, Penicillium, Aspergillus, Torulopsisspp. are coming from pollen, flowers, hives. Even aerobic spore forming Bacillus are mostly present on external surface, crop, or intestine of honey bees [11, 12, 13, 14]. The primary sources of sugar tolerant yeast are flowers and soil but the secondary sources of microbial contamination in honey are human, equipment, containers, wind, dust etc. Possible transmission routes into extracted honey including air (in the house or while the honey was packed), food handlers (from skin infections, sneezing or faecal contamination) [13].Mostly found 
microorganisms in honey are tabulated in table 1 [11]. Most of the bacteria or other microbes are in dormant state and unable to reproduce because of antibacterial activity of honey. Honey sometimes acts as a carrier of typhoid, fever, dysentery and various diarrhoea infections [9].

Table 1: Microorganisms found in Honey

\begin{tabular}{lll}
\hline Bacteria & Yeasts & Moulds \\
Alcaligens & Ascosphaera & Asperhillus \\
Achromobater & Debaromyces & Alihia \\
Bacillus & Hansenula & Bettsia alvei \\
Bacteridium & Lipomyces & Cephalosporium \\
Brevibacterium & Nematospora & Chaetomium \\
Citrobacter & Oosporidium & Coniothecium \\
Clostridium & Pichia & Hormiscium \\
Enterobacter & Saccharomyces & Peronsporoceae \\
Escherichia coli & Schizosaccharomyces & Peyronelia \\
Erwinia & Trichosporium & Triposporium \\
Flavobacterium & Torula & Uredianceae \\
Klebsiella & Torulopsis & Ustilaginaceae \\
Micrococcus & Zygasaccharomyces & \\
Neisseria & & \\
Pseudomonas & & \\
Xanthomonas & & \\
& & \\
\hline
\end{tabular}

\section{Medicinal Properties of Honey:}

Honey is a well-known ancient remedy for the treatment of infected wounds, surgical wounds, burns, skin/peptic ulcers, inflammations even it can work very well when conventional modern therapeutic agents fail. It was first reported that honey was used as drug or ointment during 21002000BC.Manuka honey (non-peroxide based) has been reported as antimicrobial agent against pathogenic bacteria such as Staphylococcus aureus, Helicobacter pylori and this is used for the treatment of wounds or stomach ulcers [15]. Honey is used for the treatment of wound healing due to its antibacterial healing property $[16,17,18]$.Even high viscous nature of honey helps to create a protective barrier to prevent infections [5].In vivo activity and treatment of ulcers, infected wounds and burns as well were reported for the Medihoney and Manuka honey [5, 19]. The topical application of honey rapidly clears the wound infection to facilitate healing of deep surgical wounds with infection [20]. The honey is useful for the healing in infected wounds that do not respond to the conventional therapy i.e. antibiotics and antiseptics [20], including wounds infected with methicillin-resistant S. aureus(MRSA) [21, 22]. The Manuka, jelly bush and pasture honeys canstimulate the monocytes, the precursors of 
macrophages, to secrete TNF- $\alpha[23,24]$ and the glycosylated proteins can induce TNF$\alpha$ secretion by macrophages, and this cytokine is known to induce the mechanism of wound repairing. So, the immunomodulatory property is essential for wound repairing. From traditional folklore, honey is used in the treatment of peptic ulcers and gastritis and it also acts as anti-inflammatory agent $[25,26]$. Raw honey also contains some antioxidant compounds such as flavonoids and other polyphenols [27]. Clinical observations have been reported of reduced the inflammation by applying honey on wounds. The removal of exudate in wounds dressed with honey to manage inflamed wounds.

\section{Antimicrobial Properties of Honey:}

It was proved in research that Manuka honey (L. scoparium)was demonstrated to be effective against several human pathogens, including E. coli, Enterobacteraerogens, Salmonella typhimurium, S. aureus [5, 28] and honey is also effective against methicillinresistant S. aureus(MRSA), $\beta$-haemolytic streptococciand vancomycin resistantEnterococci(VRE) $[29$, 30].Manuka honey (L. scoparium) is the best honey and it was reported to have an inhibitory effect against 60 species of bacteria, including aerobes and anaerobes, and Gram-positive and Gram-negative as well [31]. Even Manuka honey has enough antimicrobial activity, local production or availability, greater selectivity against medically important organisms [5]. More susceptibility with antibacterial potency of honey is located against $S$. aureus, Pseudomonas aeruginosa, Enterococcusspecies [32, 33]. Minimal inhibitory concentration (MIC) is the lowest concentration of an antimicrobial agent for microbial inhibition. The MICs of Tualang honey ranges from $8.75-25 \%$ whereas Manuka honey has 8.75-20\% against many pathogenic Gram-positive and Gram-negative bacteria [34]. The honey has some beneficial roles to attribute its antibacterial property with regards to its high osmolarity, acidity (low $\mathrm{pH}$ ) and content of hydrogen peroxide $(\mathrm{H} 2 \mathrm{O} 2)$ and non-peroxide components, i.e., the presence of phytochemical components like methylglyoxal (MGO) $[35,36]$. The antimicrobial agent in honey is hydrogen peroxide $(\mathrm{H} 2 \mathrm{O} 2)$ whose concentration is determined by relative levels of the enzyme, glucose oxidase, synthesized by the bee and catalase originating from flower pollen [37].This hydrogen peroxide is produced enzymatically in honey. The glucose oxidase enzyme is secreted from the hypopharyngeal gland of the bee into the 
nectar to make honey from the nectar. The hydrogen peroxide and acidity produced by the reaction: Glucose $+\mathrm{H} 2 \mathrm{O}+\mathrm{O} 2$ Gluconic acid $+\mathrm{H} 2 \mathrm{O} 2$. Due to acidic nature of undiluted honey, it plays significant antibacterial factor against Salmonellaspp, E. coli, Pseudomonus aeruginosa, Streptococcus pyogenes, Vibrio cholerae, Yersinia enterocolitica, Plesiomonasshigelloides,

Aeromonashydrophila, Shigellaboydi, Clostridium jejuni, Aspergillus niger, Penicilliumchrysogenum, Candida albicans, Staphylococcus aureus [38, 39, 40, 41].Honey contains acidic properties of gluconic acid and antiseptic properties of hydrogen peroxide (H2O2) [42]. Finally, higher the concentration of honey results greater the usefulness as an antibacterial agent [43].

\section{Methodology:}

\section{Natural Method of Extraction of Honey} from Beehive:

To extract honey, wax layer on the cells has to be removed first by the help of sharp knife, then it has been warmed in hot water. The combs are inserted into centrifuge and honey is carefully removed or honey is sometimes removed by pressure [44].

\section{Isolation of different kinds of bacteria using non-selective agar (LB Agar) and selective MacConkey agar with honey sample:}

Honey samples are usually microbiologically stable and can be transported and stored at ambient temperature. These samples should be protected against moisture and excessive heat [45].Sample unit must be greater than the required for analysis. The selected analytical unit of honey is $25 \mathrm{~g}$. Then the disinfection is required for the area outside of the packaging with $70 \%$ Ethanol and sample honey is removed from the jar aseptically.

Now, non-selective LB agar with $25 \mathrm{~g}$ of honey is prepared for the purpose of isolation of different kinds of bacteria. $25 \mathrm{~g}$ of honey, 25g LB agar powder and 1Lt. distilled water or deionized water are mixed and homogenized to prepare LB agar then it is serial diluted $\left(10^{\wedge}-1,10^{\wedge}-2\right.$, $\left.10^{\wedge}-3\right)$ and the mixtures are boiled to dissolve the agar and sterilized by autoclaving at $15 \mathrm{psi}, 121^{\circ} \mathrm{C}$ for $15 \mathrm{~min}$. Then different plates are prepared and incubated at $37^{\circ} \mathrm{C}$ for 24 hours overnight by adjusting $\mathrm{pH} \quad 6.8-6.9$ and finally streaking of LB agar plates is done with pure or mixed bacterial culture and these plates are incubated at $37^{\circ} \mathrm{C}$ for $24-48$ 
hours overnight to observe colony morphology.

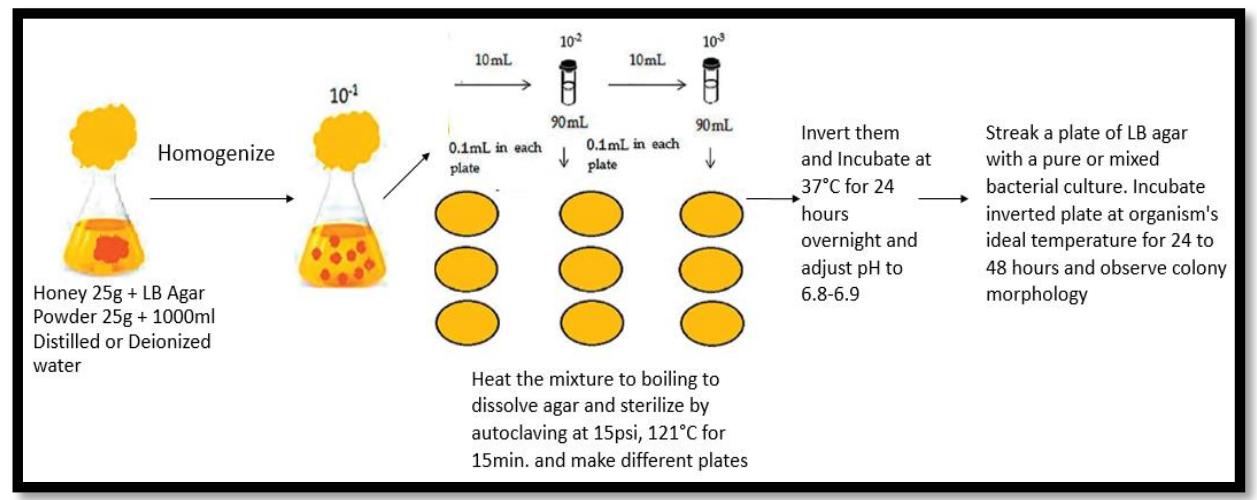

Fig. 1: Process Flow for LB agar plate preparation with honey sample and streaking the plates with pure or mixed bacterial culture

Similarly, selective MacConkey agar with $25 \mathrm{~g}$ of honey is prepared for the purpose of isolation of different kinds of gramnegative bacteria. $25 \mathrm{~g}$ of honey, $25 \mathrm{~g}$ MacConkey agar powder and 1Lt. distilled water or deionized water are mixed and homogenized to prepare MacConkey agar then it is serial diluted $\left(10^{\wedge}-1,10^{\wedge}-2,10^{\wedge}-\right.$ 3) and the mixtures are boiled to dissolve the agar and sterilized by autoclaving at $15 \mathrm{psi}, 121^{\circ} \mathrm{C}$ for $15 \mathrm{~min}$. Then different plates are prepared and incubated at $37^{\circ} \mathrm{C}$ for 24 hours overnight by adjusting $\mathrm{pH}$ 6.8-6.9 and finally streaking of MacConkey agar plates is done with pure or mixed bacterial culture and these plates are incubated at $37^{\circ} \mathrm{C}$ for $24-48$ hours overnight to observe colony morphology.

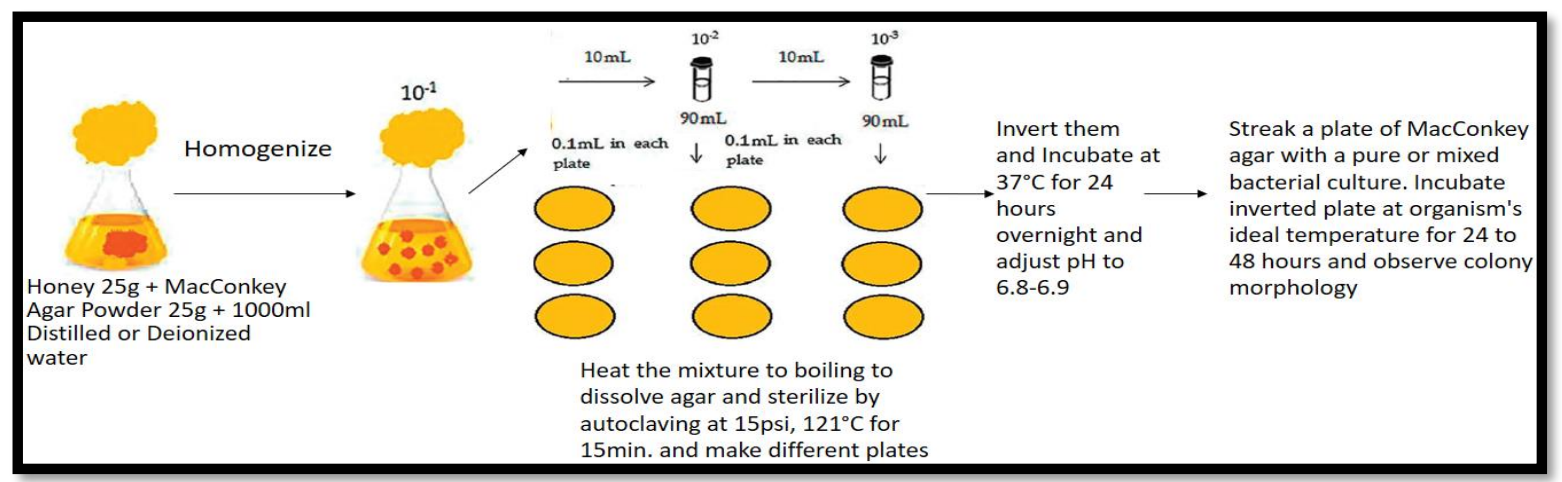

Fig. 2: Process Flow for MacConkey agar plate preparation with honey sample and streaking the plates with pure or mixed bacterial culture

\section{Characterization of isolated bacteria} with gram staining:

For gram staining,

1. Place a small drop of the culture on the labelled glass slide.
2. Spread the sample over a large surface with a pipette tip to form a thin film.

3. Allow the suspension to completely air dry. 
4.To fix the microbes to the slide, hold the slide example side up, by its edge and immediately pass the slide across a Bunsen burner fire 10-20 times. Ensure the slide isn't overheated each time.

5.Cover the whole area of microscopic organisms with Gram Crystal Violet and leave at room temperature. Flush the slide for 5 seconds under sluggish running water utilizing a wash bottle. The example ought to seem blue-violet when seen with the unaided eye.

6.Cover the microorganisms with the Gram Iodine and leave at room temperature for 1 moment. Flush the slide for 5 seconds under sluggish running water then, at that point, promptly continue to the following stage. Now the example should in any case be blue-violet.

\section{Add the Decolourizer Solution} drop-wise until the blue-violet colour is no longer visualized on the sample.

8. Rinse the slide for 5 seconds under sluggish running water utilizing a wash bottle.

9.Cover the microscopic organisms with the Gram Safranin and leave at room temperature for 1 moment. Wash the slide for 5 seconds under sluggish running water to eliminate any overabundance color.
10. Stain the slide delicately with spongy paper or permit it to air dry prior to survey under a splendid field magnifying lens. $600 \times$ amplification is satisfactory for survey microbes on the slide. Notice the focal point of the slide where microbes has been treated with all Gram Stains. An oil drenching objective might be utilized for high amplification. A drop of oil can be put straightforwardly on the slide [46-48].

\section{Microscopy of Honey:}

According to the method of the Association of Official Analytical Chemistry AOAC. The method is based on dissolving $100 \mathrm{~g}$ of the honey sample in $200 \mathrm{~mL}$ of distilled water which is further heated and acidified with $5 \mathrm{ml}$ of nitric acid $(\mathrm{HNO} 3)$ at $6 \mathrm{M}$ concentration. Filter the sample in a Buchner funnel and mark four quadrants on filter paper. Analyse using a stereoscopic microscope with a total multiplication of $100 \times$ and finally confirm the type of sediment between slide and cover slip under an optical microscope with a multiplication of $100-400 \times[49,50]$.

\section{Conclusion:}

Honey is an ancient remedy from long years back but it is now rediscovered for various medicinal properties. But honey can get contaminated by human activities 
including equipment, containers, wind, dust etc. and all the microbes present in honey are in dormant state. Non-spore forming bacteria in vegetative forms can't survive in honey whereas spore forming bacteria can't transit into vegetative forms and stay in honey and supportive of inhibitory role of honey on microorganisms. Honey is applied to wounds by diluting its initial high osmolarity and other properties like hygroscopicity, healing property, antibacterial activity etc. can inhibit the growth of microorganisms. Before commencing to the treatment of wound healing, microorganisms of honey should be isolated and their sensitivity should be assessed carefully. Chronic wound infection don't respond to antibiotic therapy but honey plays a promising role. Manuka honey is renowned globally because of its antibacterial role. Even honey plays an effective antimicrobial properties against antibiotic-resistant organisms such as MRSA, MDR etc. for the treatment of burn wounds, nosocomial infections etc. Nowadays, some standardised honeys such as Manuka honey (L. scoparium), Tualang honey (Koompassiaexcelsa) play proper antibacterial activities. The medical grade honeys like Revamil, Medihoney play topical antibacterial role because of its broad spectrum bactericidal activity, and these are applied for the treatment of topical infections caused by antibiotic resistant as well as antibiotic sensitive bacteria. These are used for therapeutic usage. Therefore it is required to study more and more natural honey for their antimicrobial activities.

\section{References:}

1. Bassey IH. In: Bee keeping, digest of selected literature on bee keeping, honey and bee wax processing, Libriservice limited, Lagos, Nigeria 1986; 22.

2. Lusby PE, Coombes AL, Wilkinson JM. Bactericidal activity of different honeys against pathogenic bacteria. Arch Med Res 2005; 36: 464-467.

3. Pamphlet of Honey Bee. American Magazine. April 21, 2002:4pp.

4. Tonks A, Cooper RA, Price AJ, Molan PC, Jones KP Stimulation of tnf-alpha release in monocytes by honey. Cytokine 2001; 14(4): 240-2.

5. Lusby PE, Coombes AL, Wilkinson JM. Bactericidal activity of different honeys against pathogenic bacteria. Arch Med Res 2005; 36: 464-467.

6. White JW. Honey. In: The Hive and the honeybee. Dadant and Sons Inc.,Hamilton Illonis, USA, 1957; 491530.

7. Crane B. A book of honey. Oxford University Press, Oxford UK 1980; 198.

8. Lee CY AND Kime RW. The use of honey for clarifying apple juice. J Apic Res. 1984; 23(1): 45-49.

9. Sackelt WG. Honey olorado State Univ. as a carrier of intestinal diseases. Bull. CExp. Stad 1919; 252: 1-18. 15.

10. Tysset C Durand C De Rantline de la Roy. Contribution to African Health Sciences Vol 7 No 3 September 2007 165 the study of intestinal microbial 
infection of healthy honeybees: Inventory of bacterial population by negative organisms. Department of Agriculture, SEA-AR, Eastern region research centres, Philadelphia, 1991; 21-55.

11. White P.B. The normal flora of the bee. Agricultural research service. US Department of Agriculture Washinton AC 1996; 301-309.

12. Gilliam $\mathrm{M}$ and Prest DB. Microbiology of Lanial honey bee (Apismelifera). Jounal of Invertebrate Pathology. 1987; 49:70-75.

13. Root AL. The ABC and XYZ of bee culture. Edward Arnold publication Ltd. London, 1993; 5-28.

14. El-leithy MA El-sibael KB. Role of microorganisms isolated from bees, its ripening and fermentation of honey. Egyptian Journal of Microbiology 1992; 75:679-681.

15. French VM, Cooper RA, Molan PC. The antibacterial activity of honey against coagulase-negative Staphylococci.

AntimicrobChemother2005; 56: 228231.

16. Van den Berg AJ, Van den Worm E, Van Ufford HC, Halkes SB, Hoekstra MJ, BeukelmanCJ. An in vitro examination of the antioxidant and anti-inflammatory properties of buckwheat honey. J Wound Care 2008; 17: 172-178.

17. Molan PC. The evidence supporting the use of honey as a wound dressing. Int J Low Extrem Wounds 2006; 5: 4054.

18. Simon A, Traynor K, Santos K, Blaser G, Bode U, Molan P. Medical honey for wound care - still the 'Latest Resort'. Evid Based Complement Alternat Med 2008; doi:10.1093/ecam/nem175.

19. Al-Waili NS, Akmal M, Al-Waili FS, Saloom KY, Ali A. The antimicrobial potential of honey from United Arab Emirates on some microbial isolates. Med Sci Monitor 2005; 11: 433-438.
20. Ahmed AK, Hoekstra MJ, Hage J, Karim RB. Honey-medicated dressing: transformation of an ancient remedy into modern therapy. Ann PlastSurg2003; 50: 143-148.

21. Natarajan S, Williamson D, Grey J, Harding KG, Cooper RA. Healing of an MRSA-colonized hydroxyureainduced leg ulcer with honey. J Dermatol Treat 2001; 12: 33-36.

22. Dunford C, Cooper RA, Molan PC. Using honey as a dressing for infected skin lesions. Nurs Times 2000; 96: 7-9.

23. Tonks AJ, Cooper RA, Jones KP, Blair S, Parton J, Tonks A. Honey stimulates inflammatory cytokine production from monocytes. Cytokine 2003; 21: 242-247.

24. Tonks A, Cooper RA, Price AJ, Molan PC, Jones KP. Stimulation of TNFalpha release in monocytes by honey. Cytokine 2001; 14: 240-242.

25. Molan PC. Why honey is effective as a medicine. 1. Its use in modern medicine. In: Munn $\mathrm{P}$, Jones $\mathrm{R}$, editors. Honey and Healing. UK: International Bee Research Association; 2001.

26. Molan PC. Why honey is effective as a medicine. 2. The scientific explanation of its effects. In: Munn P, Jones R, editors. Honey and Healing. UK: International Bee Research Association; 2001.

27. Blassa M, Candracci M, Accorsi A, Piacentini MP, Albertini M C, Piatti E. Raw millefiori honey is packed full of antioxidants. Food Chem2006; 97: 217-222.

28. Visavadia BG, Honeysett J, Danford MH. Manuka honey dressing: An effective treatment for chronic wound infections. Br J MaxillofacSurg2006; 44: 38-41.

29. Allen KL, Hutchinson G, Molan PC. The potential for using honey to treat wounds infected with MRSA and VRE. First World Healing Congress, Melbourne, Australia 2000; 10-13. 
30. Kingsley A. The use of honey in the treatment of infected wound. British $\mathrm{J}$ Nursing 2001; 10: S13-S16.

31. Molan PC. The antibacterial nature of honey. The nature of the antibacterial activity. Bee World 1992; 73: 5-28.

32. Cooper RA, Molan PC, Harding KG. Honey and gram positive cocci of clinical significance in wounds. $\mathrm{J}$ ApplMicrobiol2002; 93: 857-863.

33. Abhishek KJ, Ravichandran V, Madhvi S, Agrawal RK. Synthesis and antibacterial evaluation of 2substituted-4, 5- diphenyl-N-alkyl imidazole derivatives. Asian $\mathrm{Pac} \mathrm{J}$ Trop Med 2010; 3(6): 472-474.

34. Tan HT, Rahman RA, Gan SH, Halim AS, Hassan SA, Sulaiman SA, et al. The antibacterial properties of Malaysian tualang honey against wound and enteric microorganisms in comparison to manuka honey. BMC Complement Alternat Med 2009; 9: 34 doi: 10.1186/1472-6882-9-34.

35. Weston RJ. The contribution of catalase and other natural products to the antibacterial activity of honey: a review. Food Chemistry 2000; 71: 235 $-239$.

36. Mavric E, Wittmann S, Barth G, Henle T. Identification and quantification of methylglyoxal as the dominant antibacterial constituent of manuka (Leptospermum scoparium) honeys from New Zealand. MolNutr Foods Res 2008; 52: 483-489.

37. Weston RJ. The contribution of catalase and other natural products to the antibacterial activity of honey: a review. Food Chemistry 2000; 71: 235 $-239$.

38. O'Grady FW Lambert HP Finch RG Greenwood D. Antibiotic and Chemotherapy(7th ed), Churchill Living Stone, New York, 1997.

39. Obaseiki-Ebor EE Afonja TC. In Vitro evaluation of the anticandidiasis activity of honey distillate(HY-1) compared with that of antimycotic agents. J. Pharm. Pharmacol. 36:283284.

40. EfemSE . Recent advances in the management of Fournier's gangrene: Preliminary observations. Surgery, 1993; 113:200-204.

41. Molan PC. The antibacterial activity of honey. 1 .The nature of the antibacterial activity. Bee World 1992; 73(1): 5-28.

42. Khan FR, Abadin UI, Rauf N. Honey; Nutritional and medical Value. Medscape Today 2007. [Online] Available from: http:// www.medscape.com/viewartide/56591 $\underline{3}$.

43. Badawy OFH, Shafii SSA, Tharwat EE, Kamal AM. Antibacterial activity of bee honey and its therapeutic usefulness against Escherichia coli O157:H7 and Salmonella typhimuriuminfection. Rev SciTechnolIntEpiz2004; 23: 10111122.

44. Zwaenopoel C. Honey: Facts and Folklore. Alberta Beekeepers Association, Edononton, Canada. 1984; 24.

45. Biswadeep Chaudhuri, Shrabani Ghosh, Bholanath Mondal, Debabrata Bhadra. Preparation and characterization of carbon fibre powder (CFP)-polyvinyl alcohol (PVA) composite films showing percolation threshold behaviour. Materials Science and Engineering: B, Volume 275, 115500, 2022.

46. Association of Official Analytical Chemistry (AOAC). Official methods of analysis. 19th ed. Gaithersburg: Hardcover; 2012. 3000 p.

47. Tysset C Durand C De Rantline de la Roy. Contribution to the study of intestinal microbial infection of healthy honeybees: Inventory of bacterial population by negative organisms. Department of Agriculture, SEA-AR, Eastern region research centres, Philadelphia, 1991; 21-55.

48. Wadi M, Al-Amin H, Farouq A, Kashef H, Khaled SA. Sudanese bee 
honey in the treatment of supprating wounds. Arab Medico 1987; 3: 16-8.

49. Church D, Elsayed S, Reid O, Winston B, Lindsay R. Burn wound infections. ClinMicrobiol Rev 2006; 19: 403-434. 50. Erol S, Altoparlak U, Akcay MN, Celebi F, Parlak M. Changes of microbial flora and wound colonization in burned patients. 